\title{
Polymicrobial endophthalmitis: prevalence, causative organisms, and visual outcomes
}

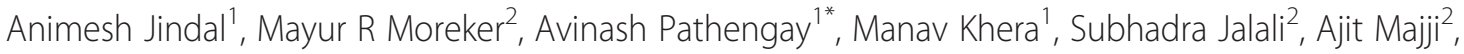
Annie Mathai ${ }^{2}$, Savitri Sharma ${ }^{3}$, Taraprasad Das ${ }^{3}$ and Harry W Flynn $\mathrm{Jr}^{4}$

\begin{abstract}
Background: The purpose of the present study is to evaluate the prevalence, causative organisms, and visual acuity outcome in patients with culture-proven polymicrobial endophthalmitis. The method used in this study is the noncomparative, consecutive case series using a retrospective analysis of patients diagnosed with polymicrobial endophthalmitis for the period 2000 to 2010.

Results: Polymicrobial endophthalmitis was identified in 43/1,107 (3.88\%) patients. Forty-two patients had two isolates, and one patient had grown three isolates, yielding a total of 87 isolates. Gram-positive cocci were the most common isolate $(n=53 ; 60.9 \%)$ including Staphylococcus epidermidis $(n=14 / 53 ; 16.1 \%)$ and Streptococcus pneumoniae $(n=13 / 53 ; 13.8 \%)$. The etiologies included posttraumatic $(n=31 / 43 ; 72.1 \%)$ and postoperative $(n=9 / 43 ; 20.9 \%)$ endophthalmitis. Antibiotic susceptibilities among Gram-positive bacteria were vancomycin (100\%) and chloramphenicol (96\%). Susceptibilities among Gram-negative bacteria were ciprofloxacin (86.4\%) and ofloxacin (81.2\%). A maximum number of secondary interventions were done in traumatic cases (38.7\%) and cases having coinfection with Gram-negative bacteria and fungus (66.7\%). Visual acuity (VA) < 20/200 was more frequently observed in posttraumatic cases $(n=27 / 31 ; 87.1 \%)$ as compared with postoperative cases ( $n=4 / 9 ; 44.4 \%$ ). Of the 43 patients, only 9 patients (20.9\%) achieved a $V A \geq 20 / 200$ on final follow-up. Four out of twelve patients (33.3\%), with fungus as one of the isolates, had a $V A \geq 20 / 200$.
\end{abstract}

Conclusions: Although polymicrobial infection in endophthalmitis is uncommon, it is generally associated with poor visual acuity outcomes especially in eyes with open-globe injuries. Coinfection with Gram-negative bacteria or fungi was associated with most unfavorable visual outcome.

Keywords: Polymicrobial, Endophthalmitis, Antibiotic susceptibilities

\section{Background}

Endophthalmitis is one of the most vision-threatening ocular complications following intraocular surgeries and open-globe injuries. The incidence of polymicrobial infection in the report of the Endophthalmitis Vitrectomy Study (EVS) Group was 9.3\% [1]. The incidence of polymicrobial endophthalmitis after open-globe injuries has been reported from $5.3 \%$ to $47.6 \%$ [2-6], while it has been reported to be $0.0 \%$ to $17 \%$ in various postoperative endophthalmitis series [6-12]. There are limited published series reporting the etiology and outcome of polymicrobial endophthalmitis [12]. No large series are

\footnotetext{
* Correspondence: avinash@lvpei.org

'LV Prasad Eye Institute, GMRV Campus, Visakhapatnam, India

Full list of author information is available at the end of the article
}

available in the literature on etiology and visual acuity (VA) outcomes of polymicrobial endophthalmitis cases.

The purpose of the present study is to evaluate the prevalence, causative organisms, and visual acuity outcomes in patients with culture-proven polymicrobial endophthalmitis in a teaching hospital.

\section{Results and discussion}

Results

Polymicrobial endophthalmitis was seen in $43(3.88 \%)$ out of 1,107 culture-proven endophthalmitis patients. There were 31 male patients as compared to 12 female patients with polymicrobial infection. Forty-two patients had grown two isolates and one patient had grown three isolates, yielding a total of 87 isolates (Table 1). 


\begin{tabular}{|c|c|c|c|c|c|c|c|}
\hline SR number & Age/gender & Setting & Visual acuity (presenting) & Primary intervention & Secondary intervention $(\mathrm{Y} / \mathrm{N})$ & Visual acuity (final) & Organisms \\
\hline 1 & 7 years/F & Trauma & PR inacc & $P P V+I O A B$ & $\mathrm{~N}$ & No PL & $\begin{array}{l}\text { Staphylococcus epidermidis, } \\
\text { Streptococcus pneumoniae }\end{array}$ \\
\hline 2 & 5 years $/ M$ & Trauma & PR inacc & $S T R+P P V+I O A B$ & $\mathrm{~N}$ & CF $2 \mathrm{~m}$ & $\begin{array}{l}\text { Alpha hemolytic Streptococcus, } \\
\text { Haemophilus influenzae }\end{array}$ \\
\hline 3 & 60 years/M & Cataract surgery & $20 / 200$ & Vit $B x+I O A B$ & N & $20 / 400$ & Bacillus, Corynebacterium \\
\hline 4 & 6 years/F & Trauma & PR inacc & $S T R+P P V+I O A B$ & $\mathrm{~N}$ & No PL & $\begin{array}{l}\text { Alpha hemolytic Streptococcus, } \\
\text { Acromonas }\end{array}$ \\
\hline 5 & 8 years/F & Trauma & PR inacc & $S T R+P P V+I O A B$ & N & No PL & Bacillus, S. pneumoniae \\
\hline 6 & 35 years $/ F$ & Trauma & PR inacc & IOFB removal + PPV + IOAB & N & CF $1 / 2 \mathrm{~m}$ & Aspergillus sp., Bacillus \\
\hline 7 & 45 years/M & Trauma & PR inacc & $S T R+P P V+I O A B$ & N & No PL & S. epidermidis, Bacillus \\
\hline 8 & 15 years/M & Trauma & PR acc & IOFB removal + PPV + IOAB & $N$ & $20 / 60$ & $\begin{array}{l}\text { Alpha hemolytic Streptococcus, } \\
\text { Clostridium }\end{array}$ \\
\hline 9 & 64 years/M & $\begin{array}{l}\text { Penetrating } \\
\text { keratoplasty }\end{array}$ & $20 / 1200$ & Vit $B x+1 O A B$ & N & $20 / 160$ & S. epidermidis, S. pneumoniae \\
\hline 10 & 36 years $/ M$ & Trabeculectomy & PR inacc & $P P V+I O A B$ & N & $20 / 40$ & S. pneumoniae, Fusarium \\
\hline 11 & 73 years/M & Cataract surgery & PR acc & $P P V+I O A B$ & $\mathrm{~N}$ & PR inacc & S. epidermidis, Aspergillus \\
\hline 12 & 8 years/M & Trauma & PR inacc & IOFB removal + PPV + IOAB & N & No PL & $\begin{array}{l}\text { S. epidermidis, Alpha hemolytic } \\
\text { Streptococcus }\end{array}$ \\
\hline 13 & 39 years $/ F$ & Trauma & PR inacc & $S T R+P P V+I O A B$ & N & PR inacc & Chrysomonads, Fusarium \\
\hline 14 & 23 years $/ M$ & Trauma & PR acc & $P P V+I O A B$ & N & $20 / 400$ & S. epidermidis, Aspergillus \\
\hline 15 & 4 years/M & Trauma & PR inacc & $S T R+P P V+I O A B$ & N & PR acc & S. epidermidis, Aspergillus \\
\hline 16 & 16 years $/ M$ & Trauma & PR inacc & IOFB removal + PPV + IOAB & N & PR inacc & S. epidermidis, S. pneumoniae \\
\hline 17 & 71 years/M & Trabeculectomy & PR acc & $S T R+P P V+I O A B$ & N & $20 / 50$ & Moraxella, S. epidermidis \\
\hline 18 & 45 years/M & Cataract surgery & $20 / 25$ & Vit $B x+1 O A B$ & N & $20 / 25$ & S. epidermidis, Aspergillus \\
\hline 19 & 18 years/M & Trauma & PR acc & $P P V+I O A B$ & N & $20 / 1200$ & S. epidermidis, Aspergillus \\
\hline 20 & 38 years/M & Trauma & PR acc & $P P V+I O A B$ & N & $20 / 40$ & S. epidermidis, Clostridium \\
\hline 21 & 60 years/M & Cataract surgery & PR acc & $P P V+I O A B$ & N & PR inacc & Corynebacterium, Aspergillus \\
\hline 22 & 38 years $/ M$ & Trauma & PR acc & $S T R+P P V+I O A B$ & Y & PR acc & $\begin{array}{l}\text { Bacillus, Alpha hemolytic } \\
\text { Streptococcus }\end{array}$ \\
\hline 23 & 14 years/M & Endogenous & Pr acc & $P P L+P P V+I O A B$ & N & No PL & S. pneumoniae, S. aureus \\
\hline 24 & 4 years $/ F$ & Trauma & PR acc & $P P V+I O A B$ & N & No PL & S. pneumoniae, H. influenzae \\
\hline 25 & 50 years $/ \mathrm{M}$ & Trauma & PR inacc & $E C C E+P P V+I O A B$ & Y & No PL & S. pneumoniae, Pseudomonas \\
\hline 26 & 57 years/M & $\begin{array}{l}\text { Penetrating } \\
\text { keratoplasty }\end{array}$ & PR acc & $P P V+I O A B$ & N & $\mathrm{CF}-1 / 2 \mathrm{~m}$ & S. pneumoniae, H. influenzae \\
\hline 27 & 7 years/F & Trauma & PR acc & $S T R+P P V+I O A B$ & Y & No PL & S. pneumoniae, E. coli \\
\hline
\end{tabular}


Table 1 Clinical profile of patients with polymicrobial endophthalmitis (Continued)

\begin{tabular}{|c|c|c|c|c|c|c|c|}
\hline 28 & 7 years $/ F$ & Trauma & PR acc & $P P L+P P V+I O A B$ & N & No PL & S. pneumoniae, Neisseria \\
\hline 29 & 3 years/M & Trauma & PR acc & $P P V+I O A B$ & N & No PL & S. pneumoniae, Pseudomonas \\
\hline 30 & 8 years/M & Trauma & PR acc & $P P L+P P V+I O A B$ & Y & No PL & S. pneumoniae, H. influenzae \\
\hline 31 & 11 years/M & Trauma & PR inaac & $C T R+P P L+P P V+I O A B$ & N & No PL & Bacillus, Enterococcus, Pantoea \\
\hline 32 & 6 years/M & Trauma & PR acc & $\begin{array}{l}\mathrm{STR}+\mathrm{PPL}+\mathrm{PPV}+\mathrm{IOAB}+ \\
\text { IOFB Removal }\end{array}$ & Y & $P L$ & Enterococcus, Stenotrophomonas \\
\hline 33 & 3 years/F & Trauma & No PL & $\mathrm{STR}+\mathrm{PPL}+\mathrm{PPV}+\mathrm{IOAB}$ & N & No PL & $\begin{array}{l}\text { Paenibacillus thiaminolyticus, } \\
\text { Enterobacter }\end{array}$ \\
\hline 34 & 1 month/M & Endogenous & $P L$ & Vit $B x+I O A B$ & N & No PL & S. pneumoniae, Pseudomonas \\
\hline 35 & 4 years/M & Trauma & PR acc & $C T R+P P L+P P V+I O A B$ & Y & $\mathrm{HM}+$ & Streptococci, Fusarium \\
\hline 36 & 57 years/F & Cataract surgery & $20 / 40$ & Vit $B x+I O A B$ & Y & $20 / 20$ & Pseudomonas, Aspergillus \\
\hline 37 & 3 years/M & Trauma & PL+ & $C T R+P P L+P P V+I O A B$ & Y & CF-2m & S. epidermidis, Corynebacterium \\
\hline 38 & 14 years/M & Trauma & PR inacc & $P P L+P P V+I O A B$ & Y & $20 / 200$ & Streptococcus mitis, Fusarium \\
\hline 39 & 5 years/M & Trauma & PR acc & $P P V+I O A B$ & Y & $P L$ & Streptococci, Pseudomonas \\
\hline 40 & 31 years/M & Endogenous & PR acc & $P P V+I O A B$ & Y & $\mathrm{HM}+$ & S. epidermidis, E. coli \\
\hline 41 & 18 years $/ F$ & Trauma & $P L$ & $P P L+P P V+I O A B+$ Ampho B & Y & $20 / 25$ & Pseudomonas, S pneumonia \\
\hline 42 & 19 years/M & Trauma & $\mathrm{HM}+$ & $\begin{array}{l}C T R+P P L+P P V+ \\
I O A B+\text { Ampho B }\end{array}$ & Y & $P L$ & Streptococci, Pseudomonas \\
\hline 43 & 34 years/F & Trauma & $P L$ & $P P V+I O A B$ & Y & $P L$ & Corynebacterium, Aspergillus \\
\hline
\end{tabular}




\section{Clinical presentation}

Overall, the presenting visual acuity was light perception in 38 patients and was greater than or equal to hand motion in 5 patients. Thirty-eight patients underwent core vitrectomy, and five patients underwent vitreous biopsy as the first intervention. In all the patients, the organisms were isolated and identified from the first vitreous sample, collected during the first procedure (vitreous biopsy/vitrectomy). Grampositive organisms were the most common isolates $(n=53$; $60.9 \%)$, followed by Gram-negative organisms ( $n=22$; $25.3 \%)$ and fungi $(n=12 ; 13.8 \%)$. Staphylococcus epidermidis $(n=14 ; 16.1 \%)$ and Streptococcus pneumoniae $(n=13$; $14.9 \%)$ were the most common organisms. The endophthalmitis categories were open-globe injury $(31 / 43 ; 72.1 \%)$, postoperative endophthalmitis $(9 / 43 ; 20.9 \%)$, and endogenous endophthalmitis $(3 / 43 ; 6.9 \%)$ (Table 2$)$.

\section{Antibiotic susceptibilities}

Gram-positive bacteria were most sensitive to vancomycin (100\%) and chloramphenicol (96\%). Gramnegative bacteria were most sensitive to ciprofloxacin (86.4\%) and ofloxacin (81.2\%) (Table 3).

\section{Secondary intervention}

Twelve out of 31 patients (38.7\%) having endophthalmitis following open-globe injury had secondary intervention as compared to postoperative $(1 / 9 ; 11.1 \%)$ and endogenous $(1 / 3 ; 33.3 \%)$ endophthalmitis. The number of patients requiring additional procedures was maximum for combination of Gram-negative and fungus (66.7\%) followed by Gram-positive and Gram-negative combination (42.1\%) (Tables 2 and 4).

\section{Visual outcomes}

An unfavorable visual outcome (VA < 20/200) resulted in 27 out of 31 patients (87.1\%) having posttraumatic endophthalmitis and four out of nine (44.4\%) patients having postoperative endophthalmitis. Combination of Gram-positive and Gram-negative organisms had the worst visual prognosis with only $10.5 \%$ patients having final VA $\geq 20 / 200$. Out of the 43 patients, only $9(20.9 \%)$ patients had a best corrected VA $\geq 20 / 200$ at final follow-up. Eight out of 12 patients (66.67\%) having fungi as one of the infecting organisms had a VA $<20 / 200$ at final follow-up visit.

\section{Discussion}

Polymicrobial eye infections present a challenge not only in identifying two or more microorganisms, but also in instituting appropriate antimicrobial therapy. In the current study and in large series, polymicrobial infections seem to occur more frequently in open-globe injuries, underscoring the non-sterile conditions under which ocular trauma occurs. Polymicrobial infections have been reported following advanced keratitis, infected scleral buckles, and dacryocystitis [13-15]. In a retrospective study from North India, Gupta et al. reported polymicrobial endophthalmitis in 8 eyes out of 47 culture-positive postoperative endophthalmitis eyes (17\%) [11]. Pijl et al. from Netherlands found polymicrobial infection in 4 out of 166 culture-positive cases (2.4\%) of postoperative endophthalmitis [12]. Anand et al., in a series of 170 culture-proven postoperative endophthalmitis, reported 3 cases $(1.8 \%)$ of polymicrobial endophthalmitis [16]. Vedantham et al., reported 3 (7.7\%) polymicrobial endophthalmitis cases in a series of 39 posttraumatic patients [17]. In the author's previous published report for the period 1991 to 1997, polymicrobial infections were identified in $12.5 \%$ (14 of 112) culture-positive postoperative cases, while it was present in $20.4 \%$ (23 of 113) culture-positive posttraumatic cases, with three trimicrobial cases [2,9]. In the current series from 2000 to 2010 , less prevalence of polymicrobial infection (3.88\%) was observed compared with the earlier report. The cause for this decrease in prevalence of polymicrobial infection is uncertain.

Gram-positive bacteria (S. epidermidis and S. pneumoniae) are the most common isolates from polymicrobial endophthalmitis in the current series, contrasting with the previous series where Gram-negative bacteria and fungus were most common isolates.

Considering the very short half-life of fluoroquinolones but good penetration in vitreous cavity, this class of antibiotics can be considered for per-oral therapy, and vancomycin can be considered for intravitreal injections. Repeat intravitreal antibiotics if needed should be based on culture sensitivity report.

Patients with posttraumatic endophthalmitis had poorer visual outcomes when compared with postoperative endophthalmitis, which is consistent with our previous series and previous reported literature [2,7-9]. Five out of nine postoperative patients (55.5\%) having

Table 2 Comparison of secondary interventions and visual outcome among different etiologies of polymicrobial endophthalmitis

\begin{tabular}{lccc}
\hline & Trauma & Postoperative & Endogenous \\
\hline Number of patients & 31 & 9 & 3 \\
Undergoing secondary intervention & $12(38.7 \%)$ & $1(11.1 \%)$ & $1(33.3 \%)$ \\
Unfavorable visual outcome $(\mathrm{VA}<20 / 200)$ & $27(87.1 \%)$ & $4(44.4 \%)$ & $3(100 \%)$ \\
\hline
\end{tabular}


Table 3 Antibiotic susceptibility of isolates in polymicrobial endophthalmitis

\begin{tabular}{lcc}
\hline Antibiotic & Sensitivity of gram-positive bacteria (\%) & Sensitivity of gram-negative bacteria (\%) \\
\hline Amikacin & 57.1 & 61.9 \\
Cefazolin & 81.1 & 33.3 \\
Ceftazidime & 61.1 & 63.1 \\
Ciprofloxacin & 82.7 & 86.4 \\
Chloramphenicol & 96 & 72.7 \\
Gentamycin & 74 & 63.6 \\
Gatifloxacin & 82.6 & 80 \\
Ofloxacin & 67.7 & 81.2 \\
Vancomycin & 100 & 45.4 \\
Moxifloxacin & 88.2 & 70 \\
\hline
\end{tabular}

polymicrobial infection had favorable visual outcome as compared with only 4 patients out of 31 (12.9\%) having posttraumatic endophthalmitis. The number of patients undergoing additional procedure was also more for posttraumatic cause $(38.7 \%)$ as compared with postoperative cause $(11.1 \%)$. We had three patients with endogenous source of infection who had polymicrobial infection, and all three had unfavorable visual outcome.

Although prevalence of fungus in our series has decreased, given the unsterile conditions under which traumatic endophthalmitis occurs and high probability of fungal contamination, intravitreal antifungal agents should be considered along with antibiotics, but decision should be individualized based on history and clinical examination. Limitations of the current study include the retrospective nature and lack of a definitive prospective treatment protocol.

\section{Conclusions}

Polymicrobial infections in endophthalmitis are uncommon and are often associated with trauma. Coinfection with Gram-negative bacteria or fungi may be associated with the most unfavorable visual acuity outcomes.

\section{Methods}

Approval was obtained from the local Institutional Review Board. All the patients who were diagnosed with endophthalmitis during the period 2000 to 2010 were analyzed. From the endophthalmitis database, information was obtained regarding the cause of endophthalmitis, microbiological work up including the vitreous isolates and their antibiotic susceptibilities, and the clinical outcomes. All patients with more than one isolate during microbiological workup were enrolled in the study.

The EVS recommendations were generally followed in postoperative endophthalmitis eyes. In endophthalmitis following open-globe injuries, three-port pars plana vitrectomy was performed in all eyes along with additional procedure if required (suturing scleral laceration, IOFB removal, endolaser, or silicone oil injection). Undiluted vitreous samples were sent immediately for microbiology evaluation. All eyes received intravitreal vancomycin $(1.0 \mathrm{mg}$ in $0.1 \mathrm{ml})$ and either amikacin $(0.4 \mathrm{mg}$ in $0.1 \mathrm{ml})$ or ceftazidime $(2.25 \mathrm{mg}$ in $0.1 \mathrm{ml})$ and additional intravitreal dexamethasone $(0.4 \mathrm{mg}$ in $0.1 \mathrm{ml})$ in postoperative cases. Intravitreal amphotericin B $(5 \mu \mathrm{g}$ in $0.1 \mathrm{ml})$ was administered on clinical suspicion based on surgeon's treatment preference. Additional procedures were recorded when intravitreal antimicrobials or pars plana vitrectomy/ vitreous lavage were repeated. Treatment and management decisions on secondary interventions were made by the individual treating physician without a predefined study protocol. Bacterial isolates were identified using Analytical Profile Index (API, bioMeriux, Marcy-l'Etoile, France). The antibiotic sensitivity was checked by Kirby Bauer disc diffusion method. Isolation of two or more different organisms from vitreous was considered to be a polymicrobial infection. The best-corrected visual acuity of less than 20/200 at final follow-up was defined as unfavorable visual outcome.

Table 4 Comparison of secondary interventions and visual outcome among different microbes in polymicrobial endophthalmitis

\begin{tabular}{|c|c|c|c|c|}
\hline & $\begin{array}{l}\text { Gram-positive and gram- } \\
\text { negative combination }\end{array}$ & $\begin{array}{l}\text { Gram-positive and gram- } \\
\text { negative combination }\end{array}$ & $\begin{array}{l}\text { Gram-positive and } \\
\text { fungus combination }\end{array}$ & $\begin{array}{l}\text { Gram negative and } \\
\text { fungus combination }\end{array}$ \\
\hline No. of patients & 12 & 19 & 9 & 3 \\
\hline Undergoing secondary intervention & $2(16.7 \%)$ & $8(42.1 \%)$ & $2(22.2 \%)$ & $2(66.7 \%)$ \\
\hline Unfavorable visual outcome (VA < 20/200) & $9(75 \%)$ & $17(89.5 \%)$ & $6(66.7 \%)$ & $2(66.7 \%)$ \\
\hline
\end{tabular}




\section{Competing interests}

The authors declare that they have no competing interests.

\section{Authors' contributions}

AJ carried out the data analysis and drafted the manuscript. MRM and MK carried out the data collection. AP is one of the treating physician and also carried out the correction of the manuscript. SJ, AM, AM, TD are the other treating physicians. SS is the microbiologist. HWFJ corrected the manuscript. All authors read and approved the final manuscript.

\section{Author details}

${ }^{1}$ LV Prasad Eye Institute, GMRV Campus, Visakhapatnam, India. ${ }^{2}$ LV Prasad Eye Institute, KAR Campus, Hyderabad, India. ${ }^{3}$ Bhubaneswar Eye Institute, LV Prasad Eye Institute, Bhubaneswar, India. ${ }^{4}$ Department of Ophthalmology, Bascom Palmer Eye Institute, Miller School of Medicine, University of Miami, Miami, FL, USA.

Received: 18 October 2012 Accepted: 18 October 2012

Published: 07 January 2013

\section{References}

1. Han PD, Wisniewski SR, Wilson LA, Barza M, Vine AK, Doft BH, Kelsey SF (1996) Spectrum and susceptibilities of microbiologic isolates in the Endophthalmitis Vitrectomy Study. Am J Ophthalmol 122:1-17

2. Kunimoto DY, Das T, Sharma S, Jalali S, Maiji AB, Gopinathan U, Athmanathan S, Rao TN (1999) Microbiologic spectrum and susceptibility of isolates: part II. Posttraumatic endophthalmitis. Endophthalmitis Research Group. Am J Ophthalmol 128:242-244

3. Affeldt JC, Flynn HW, Forster RK, Mandelbaum S, Clarkson JG, Jarus GD (1987) Microbial endophthalmitis resulting from ocular trauma. Ophthalmology 94:407-413

4. Brinton GS, Topping TM, Hyndiuk RA, Aaberg TM, Reeser FH, Abrams GW (1984) Post-traumatic endophthalmitis. Arch Ophthalmol 102:547-550

5. Alfaro DV, Roth D, Liggett PE (1994) Post-traumatic endophthalmitis: causative organisms, treatment, and prevention. Retina 14:206-21

6. Boldt HC, Pulido JS, Blodi CF, Folk JC, Weingeist TA (1989) Rural endophthalmitis. Ophthalmology 96:1722-1726

7. Das T, Kunimoto DY, Sharma S, Jalali S, Majji AB, Rao TN, Gopinathan U, Athmanathan S, Endophthalmitis Research Group (2005) Relationship between clinical presentation and visual outcome in postoperative and posttraumatic endophthalmitis in South Central India. Indian J Ophthalmol 53:5-16

8. Nobe JR, Gomez DS, Liggett P, Smith RE, Robin JB (1987) Post-traumatic and postoperative endophthalmitis: a comparison of visual outcomes. $\mathrm{Br} J$ Ophthalmol 71:614-617

9. Kunimoto DY, Das T, Sharma S, Jalali S, Majji AB, Gopinathan U, Athmanathan S, Rao TN (1999) Microbiologic spectrum and susceptibility of isolates: part I. Postoperative endophthalmitis. Endophthalmitis Research Group. Am J Ophthalmol 128(2):240-242

10. Endophthalmitis Vitrectomy Study Group (1995) Results of the Endophthalmitis Vitrectomy Study: a randomized trial of immediate vitrectomy and intravenous antibiotics for treatment of postoperative bacterial endophthalmitis. Arch Ophthalmol 113:1479-1496

11. Gupta A, Gupta V, Gupta A, Dogra MR, Pandav SS, Ray P, Chakraborty A (2003) Spectrum and clinical profile of post cataract surgery endophthalmitis in North India. Indian J Ophthalmol 51:139-145

12. Pijl BJ, Theelen T, Tilanus MA, Rentenaar R, Crama N (2010) Acute endophthalmitis after cataract surgery: 250 consecutive cases treated at a tertiary referral center in the Netherlands. Am J Ophthalmol 149:482-487

13. Wong T, Ormonde S, Gamble G, McGhee CNJ (2003) Severe infective keratitis leading to hospital admission in New Zealand. Br J Ophthalmol 87:1103-1108

14. Pathengay A, Karosekar S, Raju B, Sharma S, Das T, Hyderabad Endophthalmitis Research Group (2004) Microbiologic spectrum and susceptibility of isolates in scleral buckle infection in India. Am J Ophthalmol 138:663-664

15. Brook I, Frazier EH (1998) Aerobic and anaerobic microbiology of dacryocystitis. Am J Ophthalmol 125:552-554
16. Anand AR, Therese KL, Madhavan HN (2000) Spectrum of aetiological agents of postoperative endophthalmitis and antibiotic susceptibility of bacterial isolates. Indian J Ophthalmol 48:123-128

17. Vedantham V, Nirmalan PK, Ramasamy K, Prakash K, Namperumalsamy P (2006) Clinico-microbiological profile and visual outcomes of post-traumatic endophthalmitis at a tertiary eye care center in South India. Indian J Ophthalmol 54:5-10

doi:10.1186/1869-5760-3-6

Cite this article as: Jindal et al:: Polymicrobial endophthalmitis: prevalence, causative organisms, and visual outcomes. Journal of Opthalmic Inflammation and Infection 2013 3:6.

\section{Submit your manuscript to a SpringerOpen ${ }^{\mathcal{D}}$ journal and benefit from:}

- Convenient online submission

- Rigorous peer review

- Immediate publication on acceptance

- Open access: articles freely available online

- High visibility within the field

- Retaining the copyright to your article

Submit your next manuscript at $>$ springeropen.com 